\title{
Standard Regression of Chinese Curriculum in Engineering Vocational Colleges
}

\author{
Yonghong $\mathrm{Ao}^{1, *}{ }^{*}$ Hui $\mathrm{Li}^{1}$ Hui Shen ${ }^{1}$ \\ ${ }^{1}$ Chengdu Vocational \&Technical College of Industry, Chengdu, Sichuan 610218, China \\ *Corresponding author. Email: $191029211 @ q q . c o m$
}

\begin{abstract}
Under the new situation, the reform of Chinese courses in higher vocational colleges has become an inevitable era. However, due to factors such as the inversion of the teaching subject, the teaching of Chinese courses in higher vocational colleges is in a difficult position. Chinese courses in higher vocational colleges urgently need to return to the standard and reflect "professional characteristics". Based on lifelong learning, the research clarified the value demands of "student-oriented knowledge view and development-based curriculum view", and constructed the "Double Four" basic model of Chinese curriculum reform in higher vocational colleges. The reform of Chinese curriculum in higher vocational colleges should focus on professional core literacy, reset the curriculum objectives, restructure the curriculum system, reset the teaching material system, and reuse teaching methods, so as to cultivate more high-quality technical talents for service development and improve vocational education talent supply capacity.
\end{abstract}

Keywords: Higher vocational college, Teaching reform, Chinese teaching, Standard regression.

\section{INTRODUCTION}

At present, the supply side and the industrial demand side of talent training in higher vocational colleges cannot fully adapt to the structure, quality and level, and the problem of "two skins" still exists. There into, the model of talent cultivation is one of the biggest attributions. As an important part of college education, higher vocational Chinese curriculum still follow the college Chinese teaching mode and single classroom teaching mode, "neither different from each other due to the different training objectives, types and modes of talents in various colleges and universities, nor different from each other due to the different training objectives and specifications of various majors" [1]. Amid the new era, engineering higher vocational Chinese curriculum should highlight its "vocational characteristics", follow the teaching rules of higher vocational education, align with the knowledge, ability and quality requirements of professional talents, and cultivate more high-quality technical

*Fund: This paper is the periodical achievement of the educational research project "Research on the "Double Fourth" Teaching Mode of Chinese in Vocational Colleges from the Perspective of Lifelong Learning" (2015YZ03) in Chengdu. and technical talents to serve the economic and social development.

\section{THE TIMES INEVITABILITY OF CHINESE CURRICULUM REFORM IN ENGINEERING VOCATIONAL COLLEGES}

\subsection{The New Requirements of the New Economic Era}

At present, China's economic and social development has entered a new economic era with knowledge economy, network economy, lowcarbon economy, capital economy and new technology economy as its core. Against such a backdrop, the industry is also accelerating its transformation and upgrading towards a new industrial development model with "technology, quality and innovation" at its core, which requires a lot of spirit, innovative spirit, international vision, and strong practical application ability of skillful craftsman. Also, this puts forward higher requirements for forging knowledge-oriented, skillbased and innovative labor force, as well as professional knowledge, operation skills and 
professional accomplishment. As such, Chinese teaching in higher vocational colleges needs to innovate the training mode of skilled personnel to provide support for improving the quality of workers and promoting the transformation of economic development mode.

\subsection{The New Requirement Put Forward by the Higher Vocational Education Development}

Given that economic globalization and industrial information have accelerated the development of vocational education modernization, it is of great importance for vocational education to train students how to adapt to the future economic and social needs and the great changes in the world of work and life. We should promote the innovation of personnel training mode, deepen the reform of students' learning mode and teaching mode, and cultivate students' vocational adaptability, comprehensive vocational ability and sustainable development ability, emphasized in The Decision of the State Council on Accelerating the Development of Modern Vocational Education. With the acceleration of vocational education modernization, it is an inevitable choice for vocational education personnel training and higher vocational Chinese curriculum reform to cultivate students' vocational core qualities for future career, life, study and development.

\subsection{The New Requirement Put Forward by the New Curriculum Reform of Higher Vocational Colleges}

Although the new curriculum reform of higher vocational colleges is advancing in full swing, the reform is almost carried out in the field of professional curriculum, and the reform of higher vocational Chinese curriculum has not been deeply explored. In higher vocational education, Chinese curriculum, an indispensable existence, has unique aesthetic significance, humanistic value and instrumental performance, which is of great significance to the cultivation and establishment of socialist core values. Therefore, it is imperative to conduct the new reform of Chinese teaching in higher vocational education. Plus, the Chinese lessons should have practical training, and Chinese classes can also have practical training bases, which will evolved as the new trend of Chinese curriculum reform in higher vocational colleges in the future.

\section{THE DILEMMA OF CHINESE CURRICULUM TEACHING IN ENGINEERING VOCATIONAL COLLEGES}

\subsection{The College Has Placed the Chinese Curriculum in a "Remote Corner"}

As things stand, many higher vocational colleges attach more importance to specialty than foundation, and set their curriculum randomly. Of that, the Chinese curriculum is listed as optional curriculum. Some of them even cancel Chinese curriculum and replace them with curriculum such as "craftsman spirit", "practical writing", "industrial culture" and "business etiquette". As a result of performance appraisal, appraisal first, professional title appraisal and other aspects of biased, the selfesteem of Chinese teachers frustrated, enthusiasm regressive.

\subsection{Teachers Are in the "Pseudo-center" of Classroom Teaching}

Due to the lack of enterprising consciousness, the aging knowledge structure, the weak information teaching ability, the weak integration of teaching resources and the poor teaching effect, some teachers have vague cognition of the curriculum objectives and curriculum positioning, and cannot precisely set the curriculum objectives based on the personnel training objectives and students' learning needs. As such, these teachers often advocate taking knowledge as the only teaching content, ignoring the forging of students' ability and accomplishment, so that they cannot grasp the focus of higher vocational Chinese curriculum teaching and reform.

\subsection{Students Are at the "Edge" of the Curriculum}

In Chinese teaching in higher vocational colleges, teachers are in the upper role and students are in the lower role. Teachers are "knowledge authorities" and "knowledge dis-seminators", while students are "poor in knowledge" and in a passive position. Hence, Chinese teaching in higher vocational colleges has always been confined to the fixed setting of textbooks, faithful to the curriculum plan, and instilled knowledge to students from the outside. As a mere container of knowledge, students' acquisition of knowledge, skills and literacy becomes a single cognitive activity, unable 
to transcend the limited horizon between teachers and students, unable to construct an equal dialogue between teachers and students. But a bigger point is that, the subjective initiative of students is greatly limited, teachers become the subject of teaching, students become the object, and students have been in the most edge of curriculum teaching.

\section{THE PROPOSITION OF "DOUBLE FOUR" IN HIGHER VOCATIONAL CHINESE CURRICULUM REFORM BASED ON LIFELONG LEARNING}

\subsection{The Characteristics and Requirements of Lifelong Learning}

Lifelong learning was first proposed by French theorist and practitioner Paul Lengrand in 1965. Under the active advocacy of UNESCO, it quickly evolves as an international educational trend of thought. Lifelong learning refers to the continuous learning process throughout a person's life to meet the needs of social development and individual development. It is characterized by lifelong, universal and widespread characteristics [2].

The theory of lifelong learning holds that educators must set up the thought of lifelong education, so to speak, every teacher should constantly develop and improve himself according to the development of the society and the changes of The Times, and constantly update the educational concept and professional knowledge and ability structure, so as to achieve the requirements of the educational reform on the role of teachers. Also, this theory advocates that students should learn to study, with higher consciousness of learning, independent learning ability and more diversified comprehensive ability. As is universally recognized, it is not possible for students to learn every knowledge and skill they will need in the future. The function of a school is to equip students with the capacity for lifelong learning, that is, the collection of knowledge, skills and attitudes necessary for personal self-realization, lifelong development, integration into mainstream society and full employment, including the ability to communicate in one's mother tongue, in a foreign language, in mathematics and science and technology, in digitization, in learning to learn, in interpersonal communication and in fulfilling civic duties, in entrepreneurship, and in cultural expression [3]. As such, the knowledge gained via school education alone does not represent the ability to work, still less the ability to survive. Only with the ability of lifelong learning can we keep pace with The Times. And schools should pay attention to the diversified needs of students' learning, mobilize their learning potential, pay attention to the cultivation of students' lifelong learning ability, and let students learn lifelong learning is the new requirement of the Chinese curriculum reform of vocational colleges endowed by The Times.

\subsection{The Value Appeal of Higher Vocational Chinese Curriculum Reform}

\subsubsection{A View of Knowledge Based on Life}

Since knowledge is inherent, open and generative, so it is imperative to construct individual knowledge through communication activities in specific situations. From the perspective of lifelong learning, we should attach more important to the students' dominant position in the Chinese curriculum study in higher vocational colleges. While highlighting the characteristics of vocational education, it also gives consideration to the unification of the instrumentality and humanity of the Chinese subject. And the teaching should focus on students' diverse needs, mobilize students' learning potential, the disadvantages of existing rigidity Chinese teaching in higher vocational colleges, and pay attention to cultivate students' humane quality and practical ability, summarizes the formation and industry, industry, professional, professional match with broad applicability of teaching mode, to guide students to participate in the initiative, diversification and individuality of study, improving the professional application value of the Chinese curriculum in higher vocational colleges. At the same time, teaching should pay attention to the dynamic generation of the teaching process, also the active participation and dynamic participation of students, from one-way knowledge infusion to the equal dialogue between teachers and students, so as to achieve the knowledge acquisition, emotional experience, skills overlay and personality improvement of students.

\subsubsection{Developing a Standard Curriculum View}

In effect, the vocational education training objectives, not to develop a passive "knowledge storage", also is not a passive skills "robot", but 
based on the professional needs and the needs of the development of the future long-term and comprehensive analysis of professional role, on the basis of core literacy, to open a multidimensional thinking orientation, give prominence to the students' ability to shape and development of the standard. Chen Huishu (2019) hold that simple knowledge accumulation cannot meet students' development needs. The Chinese curriculum in higher vocational colleges should focus on how to "enable students to accumulate knowledge and skills as well as increase their self-experience and self-development ability in the process of solving various learning problems through the curriculum, which is highlighted by the development of learning ability and the profound understanding of the cognitive path of the learning discipline and specialty. Therefore, based on the scientific and sustainable development of students, Chinese curriculums in higher vocational colleges should break through the pattern of copying knowledge and accumulating knowledge for students, and turn to increasing students' experience, developing students' cognition and forming their problemsolving ability, so as to achieve "students and self, students and others and society, students and nature, students and positions, students and scenes" equal dialogue, which is the current higher vocational education Chinese curriculum reform the original intention.

\subsection{Constructing the Basic Model of "Double Four" in the Chinese Curriculum Reform of Higher Vocational Colleges}

The Chinese curriculum in higher vocational colleges needs to clarify four tasks. One is the standard level of Chinese curriculum — "Chinese curriculum goal", that is, "what is the Chinese accomplishment that students are expected to have"; Second, the specific form of Chinese curriculum — "Chinese curriculum content", that is, "What should be taught in general" to effectively achieve the goal of Chinese literacy [4]. Third, the specific form of Chinese teaching material "Chinese teaching material content", or "what can be usually used to teach"; Fourth, the level of Chinese teaching — "Chinese teaching content", that is, "what needs to be taught or what is best to be taught" [4].

Compared with other colleges, the Chinese teaching in higher vocational colleges should be quite different and highlight its "vocational education" characteristics to a greater extent. The new curriculum reform is by no means limited to the specialized curriculum, but we should clarify the four levels of the vocational education in vocational Chinese. Higher vocational education of Chinese curriculum in Chinese teaching in vocational colleges in position, goals, standards, functions and so on to rethink and positioning, so as to establish a scientific and reasonable cognitive, language education in current vocational education restructuring Chinese education content, the creation of new Chinese education practice, practice link, so as to realize the effective language classroom, providing better service to the implementation of the students' lifelong development goals.

As mentioned above, the "Double Four" teaching mode of Chinese language in higher vocational colleges is proposed, that is, "four links and four practices" (hereinafter referred to as "Double Four"). "Four links" refers to the teaching standards link professional standards, teaching reconstruction links industrial culture, curriculum design links professional culture, and practice and training links enterprise requirements. "Four practices" refers to actual diagnosis, real setting, experimental understanding and practical feedback. Amid the "four links and four practices", teaching pays more attention to practice, and is no longer a single curriculum, method system and evaluation standard, but a combination of industrial culture, enterprise needs, ability requirements and other elements. Moreover, the learning is more applicable to the workplace, and the teaching scene is no longer a simple classroom. It can be in the workshop, in the store, or in a specific place. Students can change their subject status at any time according to the teaching task, and they can leap freely between the two identities of "student" and "apprentice". Only in this way can the studentoriented knowledge view and development-oriented curriculum view be fully reflected and the value pursuit centered on professional accomplishment be perfectly realized. 


\section{PROMOTING THE REFORM OF HIGHER VOCATIONAL CHINESE CURRICULUM WITH THE VOCATIONAL CORE ACCOMPLISHMENT AS THE CORE}

\subsection{Resetting of Curriculum Objectives}

The orientation of Chinese curriculum objectives determines the training direction of students' Chinese literacy and teachers' teaching practice. Hence, the Chinese curriculum in higher vocational colleges must be subordinate to and dependent on the nature and requirements of vocational education, break the traditional narrow curriculum orientation based on elitism and orientation, and focus on the cultivation of students' vocational core qualities, so that students can "learn for survival". Also, the Chinese curriculum should be employment-oriented, improve the structure of students' key abilities such as knowledge and skills, strengthen the instrumentality while placing equal emphasis on the instrumentality and humanity, students' knowledge application and thinking ability, coupled with students' potential for future development, so as to guide students to learn to learn, cooperate, survive, be a behave himself, and then focus on the development of students' "whole person".

\subsection{The Reconstruction of Curriculum System}

Based on the connotation of "four links and four practices" and with reference to the idea of professional groups, the Chinese curriculum group in higher vocational colleges is constructed, which is integrated, classified and stratified, and three types of Chinese curriculum systems, namely standard, extended and promoted, are set up respectively. The standard curriculum is mainly based on the curriculum standards, integrating the universal and universal contents into a curriculum system suitable for all majors in the university, mainly including cultural expression ability, language communication ability, social responsibility, virtue and other aspects. The extended curriculum is to integrate and form a curriculum system of medium difficulty level according to the development needs of students of different levels and foundations, which mainly include literary aesthetics, scientific and humanistic qualities, environmental awareness and other aspects. The upgraded curriculum system is mainly a curriculum system that meets the needs of students' personalized development, mainly including research ability, innovative spirit and other aspects. The three curriculum systems, corresponding to different student needs, promote and guide students to return to the center of higher vocational Chinese curriculum teaching from the edge, give consideration to humanity on the basis of tool, and students are no longer the objects to be educated and shaped. The teaching setting should "take the student's needs as the center, strive to guide the student, make them establish the selfconscious, active study attitude", and make the curriculum system "carry out the principle of the organic unity of nature, society and self, and realize the development goal of the whole person", making the Chinese teaching become a real valuable existence.

\subsection{Resetting of New Textbooks}

As the goal of the curriculum, the teaching material is the concrete form of the curriculum orientation. "Teaching standards link professional standards, teaching reconstruction link industrial culture, curriculum design link professional culture, practice and training link enterprise requirements", which just emphasizes that the selection and development of Chinese curriculum materials in higher vocational colleges must be combined with the school's reality, closely linked to the connotation of professional construction. In recognition of that fact, the construction of teaching materials should emphasize the close relationship between comprehensive basic Chinese learning and professional skill training, so that the content design, task setting and talent training plan can be closely combined, which not only gives full play to the function of Language tools in higher vocational colleges, but also focuses on the cultivation of students' ability of life-long learning, innovation and development. Also, it should reflect economic development and social progress. As higher vocational education is closely related to economic and social development, therefore, the contents of textbooks must highlight the characteristics of The Times and "timely impart the concepts, achievements and industrial development trends of science and technology, innovation and development to prospective professionals, so as to expand their knowledge, broaden their horizon, observe social development and changes, understand professional cutting-edge technologies, and provide them with information support and 
experience accumulation for revising and improving their career planning". Furthermore, we should give priority to the use of modern information means to develop new forms of electronic teaching materials, the traditional paper teaching materials and quality online open classes and other digital teaching resources appropriate integration, effective expansion of teaching resources [5]. Plus, it is necessary to reflect the essence of excellent traditional culture, improve the appreciation ability of future professionals, cultivate healthy aesthetic taste, expand cultural vision, and cultivate "Great Country Craftsmen" in the new era.

\subsection{Application of Teaching Methods}

Teaching should highlight the elements of teaching organization and cultivate students' professional core qualities in practical teaching [6]. Teachers should pay attention to the application of "actual diagnosis, real scene creation, experimental understanding and practical feedback". Among them, the actual diagnosis refers to the diagnosis which fully analyzes the situation and selects three types of curriculum: standard, extended, and promoted. With respective to real scene creation, for example, the "marketing skills" in the teaching, the first step is to play the campaign video of the top five contestants in the "job application show" and create a teaching scene, which not only creates a teaching atmosphere, but also enables students to review the "show me" skills in the analysis and discussion, so as to enter the "simulation exercise". It not only helps students to complete the teaching tasks, but also enables them to get familiar with the "simulated" professional working environment, laying a sound foundation for the cultivation of their professional core qualities. As for experimental understanding, marketing skills "teaching as mentioned above, when entering into the actual practice, the teaching place can be shifted to the "4S" training workshop of Automotive Engineering College to do the real car marketing training. This undoubtedly cultivates students' abilities of teamwork, communication and coordination, innovation and creation. For the practical feedback, whether it is humanistic accumulation, aesthetic cultivation, or "simulation" training, students' learning effect and audience evaluation are timely fed back, thus forming a complete closed loop and promoting the cultivation and improvement of students' knowledge, ability and accomplishment.

\section{CONCLUSION}

Over the past few years, the Chinese curriculum reform in higher vocational colleges has achieved sound results, and some theoretical achievements and practical experience suitable for the local school have also been obtained. But the standard regression for Language curriculum in higher vocational colleges is not only the responsibility of language teachers, but also requires the full cooperation and continuous efforts of the school and relevant government departments. Only in this way can we greatly enhance the supply capacity of personnel training in higher vocational education and provide strong intellectual support and manpower support for regional economic and social development.

\section{AUTHORS' CONTRIBUTIONS}

Yonghong Ao was responsible for framework design, and wrote the manuscript with Hui Li; Hui Shen contributed to revising and editing.

\section{REFERENCES}

[1] Wang Chunfeng. Research on the Teaching Reform of Vocational Chinese Curriculum [J]. Journary of Qiqihar Institute of Engineering,2009,3(02): 23-26.

[2] 360Baike.Lifelong Learning [DB/OL]. https://baike.so.com/doc/6020619. 6233616.html.2020-10-14.

[3] Teng Meifang, Sheng Qunli.Assessing Scientific Literacy Fosters Key Competencies - OECD/PISA Conception, Design \& Assessment of Scientific Literacy [J]. Journal of Distance Education, 2009,17(03):28-36.

[4] Wang Rongsheng. New Curriculum Standard \& Chinese Content [M].Guangxi: Guangxi Education Press, 2004: 1-5.

[5] Pan Guiyun.Optimization of Language Teaching Resources in Higher Vocational Colleges Based on The Role of Public Foundation $[\mathrm{J}]$. Chinese Vocational and Technical Education,2019(08):17-20.

[6] Lin Yinong. Return to the standard: Teaching reform of college Chinese to professional Chinese in higher vocational colleges $[\mathrm{J}]$. Journal of Chinese Literature, 2015(14): 129132. 